\title{
MELHORES PRÁTICAS PARA REDUÇÃO DE FLEBITES EM UM HOSPITAL ONCOLÓGICO: UM RELATO DE CASO
}

\section{INTRODUÇÃO E OBJETIVO}

A flebite é uma manifestação local frequente da terapia intravenosa periférica administrada por meio de um cateter periférico. Apesar de ser frequente, é considerada como não desejada para o paciente e a quantificação e análise compõem o quadro de indicadores de qualidade assistencial.

O aparecimento da flebite compromete o planejamento assistencial do paciente, podendo gerar outros problemas à sua saúde, bem como aumentar o tempo de internação.

Sendo assim, foi criado um projeto multidisciplinar com o objetivo de desenvolver ações visando diminuir os casos e danos causados pela flebite.

\section{MATERIAL E MÉTODOS}

1) Escolha de uma unidade para realização do piloto;

2) Discussão das principais causas do aumento do número de casos de flebite com a equipe assistencial (brainstorming) ;

3) Atualização do protocolo de prevenção e tratamento de flebite;

4) Confecção de um fluxo para indicação da melhor via de administração das medicações;

5) Treinamento da equipe de enfermagem da unidade piloto;

6) Criação de uma ferramenta de interconsulta para acionamento do Grupo de Cateteres e Terapia Infusional (GCATI), referência na passagem de cateter;

7) Implantação do enfermeiro de referência para indicação de passagem de cateter PICC;

8) Criação dos kits de materiais de punções periféricas;

9) Conscientização sobre a importância das notificações.

\section{RESULTADOS E DISCUSSÃO}
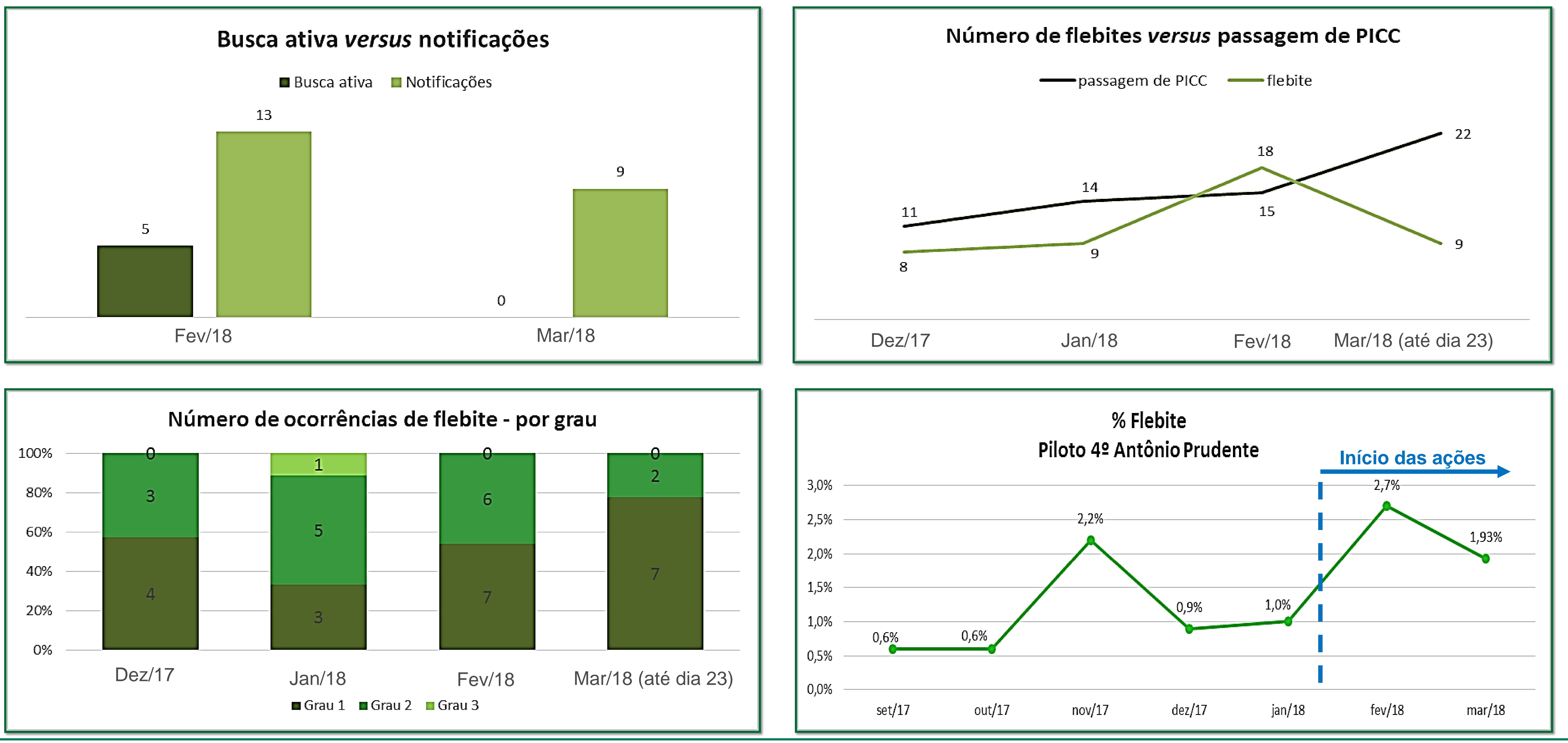

\section{CONCLUSÃO}

A qualidade no atendimento prestado e a segurança gerada aos nossos clientes é resultado do trabalho de toda equipe multidisciplinar. Este projeto nos mostrou que a junção de diferentes áreas trabalhando em um único objetivo gera ações mais efetivas e com maior chance de resultados positivos. Após implementação das ações desenvolvidas, foi possível observar ausência de flebite graus 3 e 4, aumentando as notificações das de grau 1. Também foi identificado indicação precoce de cateter PICC, conforme terapia endovenosa proposta. Em relação ao indicador de flebite, na unidade piloto o resultado foi de 2,70\% em Fevereiro/18 e 1,93\% em Março/18. 